\title{
Epicardial Fat Volume and Aortic Stiffness in Healthy Individuals: A Quantitative Cardiac Magnetic Resonance Study
}

\section{Epikardiales Fettvolumen und aortale Steifigkeit bei gesunden Menschen: eine quantitative Analyse mittels MRT des Herzens}

\author{
Authors \\ A. Sprinkart ${ }^{1,3}$ \\ Affiliations \\ Radiology, University Hospital Bonn, Germany \\ Philips Healthcare, Hamburg, Germany \\ Institute of Medical Engineering, Ruhr-University Bochum, Germany
}

R. Homsi ${ }^{1}$, D. Thomas ${ }^{1}$, J. Gieseke ${ }^{2}$, M. Meier-Schroers ${ }^{1}$, D. Dabir ${ }^{1}$, D. Kuetting ${ }^{1}$, J. A. Luetkens ${ }^{1}$, C. Marx ${ }^{1}$, H. H. Schild ${ }^{1}$,

\author{
Key words \\ epicardial fat \\ aortic stiffness \\ - CMR \\ pulse wave velocity \\ - heart
}

\section{Zusammenfassung \\ $\nabla$}

Ziel: Das Ziel war die Messung des epikardialen Fettvolumens sowie der aortalen Steifigkeit (bestimmt anhand der aortalen Pulswellengeschwindigkeit $(P W V)$ ) bei Gesunden, sowie die Untersuchung möglicher Zusammenhänge zwischen diesen Maßen, Body Mass Index (BMI) und Alter.

Material und Methoden: 58 gesunde Studienteilnehmer (29 Männer; mittleres Alter 44,7 $\pm 13,9$ Jahre [J]) wurden mittels Kardio-MRT bei 1,5 Tesla untersucht. Die Berechnung der PWV erfolgte mittels 2D-Flussmessung. Das epikardiale Fettvolumen (EFV) wurde anhand einer 3D-mDixon-Sequenz ermittelt. Es erfolgte eine Gruppeneinteilung nach Alter in $<45 \mathrm{~J}(\mathrm{n}=30 ; 33,4 \pm 6,6 \mathrm{~J})$ und $>45 \mathrm{~J}(\mathrm{n}=28$; $56,7 \pm 8,4 \mathrm{~J})$ sowie nach BMI in $<25 \mathrm{~kg} / \mathrm{m}^{2}(\mathrm{n}=28$; BMI $\left.21,9 \pm 2,5 \mathrm{~kg} / \mathrm{m}^{2}\right)$ und $>25 \mathrm{~kg} / \mathrm{m}^{2}(\mathrm{n}=30 ; 28,7 \pm$ $4,0 \mathrm{~kg} / \mathrm{m}^{2}$ ). Die Gruppen wurden untereinander verglichen und Zusammenhänge wurden mittels Kovarianzanalysen untersucht.

Ergebnisse: Die Mittelwerte von PWV und EFV (bezogen auf die Körperoberfläche) waren 6,9 $1,9 \mathrm{~m} / \mathrm{s}$ und $44,2 \pm 25,0 \mathrm{ml} / \mathrm{m}^{2}$. Die Gruppe der älteren Personen hatte signifikant höhere PWVund EFV-Werte als die jüngere Gruppe (PWV = $7,9 \pm 2,0 \mathrm{~m} / \mathrm{s}$ vs. $6,0 \pm 1,2 \mathrm{~m} / \mathrm{s} ; \quad E F V=54,7 \mathrm{ml} / \mathrm{m}^{2}$ vs. $34,5 \mathrm{ml} / \mathrm{m}^{2}$; jeweils $\mathrm{p}<0,01$ ), ohne einen signifikanten Unterschied bezüglich BMI und Geschlecht. Übergewichtige Personen (BMI $>25 \mathrm{~kg} /$ $\mathrm{m}^{2}$ ) hatten signifikant höhere EFV-Werte als die Gruppe mit einem BMI $<25 \mathrm{~kg} / \mathrm{m}^{2}(\mathrm{EFV}=56,1 \pm$ $27,1 \mathrm{ml} / \mathrm{m}^{2}$ vs. $\left.31,5 \pm 14,6 \mathrm{ml} / \mathrm{m}^{2} ; \mathrm{p}<0,01\right)$, ohne signifikante Unterschiede in der PWV. Die Kovarianzanalyse zeigte eine signifikante Korrelation zwischen EFV und PWV, auch nach Adjustierung für das Alter $(p=0,025)$.

Schlussfolgerung: Das EFV und die PWV zeigen nicht nur einen Zusammenhang mit dem Alter, sondern auch untereinander, unabhängig vom Alter. Eine metabolische und pro-inflammatorische Aktivität bei erhöhtem epikardialem Fettvolumen

\section{Abstract \\ $\nabla$}

Purpose: To determine epicardial fat volume (EFV) and aortic stiffness (assessed by aortic pulse wave velocity (PWV)) in healthy individuals, and to investigate the relationship of these parameters, and their association with body mass index (BMI) and age.

Materials and Methods: 58 subjects (29 men, mean age $44.7 \pm 13.9$ years[y]) underwent a CMR exam at 1.5 Tesla. A $2 \mathrm{D}$ velocity-encoded CMR scan was acquired to determine PWV. The EFV was measured based on a $3 \mathrm{D}$-mDixon sequence. Group comparisons were made between younger (age <45y; $\mathrm{n}=30$; mean age $33.4 \pm 6.6 \mathrm{y})$ and older ( $>45 \mathrm{y}$; $\mathrm{n}=28$; $56.7 \pm 8.4 \mathrm{y})$ subjects and between subjects with a BMI $<25 \mathrm{~kg} / \mathrm{m}^{2}(\mathrm{n}=28$; BMI $21.9 \pm 2.5 \mathrm{~kg} /$ $\left.\mathrm{m}^{2}\right)$ and $\mathrm{a} B \mathrm{BMI}>25 \mathrm{~kg} / \mathrm{m}^{2}\left(\mathrm{n}=30 ; 28.7 \pm 4.0 \mathrm{~kg} / \mathrm{m}^{2}\right)$. Associations between the determined parameters were assessed by analyses of covariance (ANCOVAs). Results: The mean values of PWV and EFV (normalized to body surface area) were $6.9 \pm 1.9 \mathrm{~m} / \mathrm{s}$ and $44.2 \pm 25.0 \mathrm{ml} / \mathrm{m}^{2}$, respectively. The PWV and EFV were significantly higher in the older group (PWV=7.9 $\pm 2.0 \mathrm{~m} / \mathrm{s}$ vs. $6.0 \pm 1.2 \mathrm{~m} / \mathrm{s}$; $\mathrm{EFV}=54.7 \mathrm{ml} / \mathrm{m}^{2}$ vs. $34.5 \mathrm{ml} / \mathrm{m}^{2} ; \mathrm{p}<0.01$, each), with no significant differences in BMI or sex. In the overweighted group the EFV was significantly higher than in subjects with a BMI $<25 \mathrm{~kg} / \mathrm{m}^{2}$ $\left(\mathrm{EFV}=56.1 \pm 27.1 \mathrm{ml} / \mathrm{m}^{2} \quad\right.$ vs. $\quad 31.5 \pm 14.6 \mathrm{ml} / \mathrm{m}^{2}$; $\mathrm{p}<0.01$ ) but without a significant difference in PWV. ANCOVA revealed a significant correlation between EFV and PWV, also after adjustment for age $(\mathrm{p}=0.025)$.

Conclusion: An association was found between age and EFV as well as PWV. EFV and PWV were related to each other also after adjustment for age. The metabolic and pro-inflammatory activity found with increased epicardial fat volume may promote the development of atherosclerosis and aortic stiffness. CMR may be valuable for future studies investigating the relationship between 
könnte die Entwicklung einer Atherosklerose und einer erhöhten aortalen Steifigkeit verstärken. Die Kardio-MRT eignet sich zur Untersuchung der Zusammenhänge von EFV und PWV in weiterführenden Studien bei Patienten mit kardiovaskulären Risikofaktoren.

Kernaussagen:

- EFV und PWV können mittels Kardio-MRT in nur einer Untersuchung bestimmt werden.

EFV und aortale Steifigkeit sind mit erhöhtem kardiovaskulärem Risiko verbunden.

- EFV und aortale Steifigkeit korrelieren miteinander, möglicherweise aufgrund gemeinsamer pro-inflammatorischer Mechanismen.

\section{Introduction}

$\nabla$

Subclinical aortic vascular damage with consecutive aortic stiffness can be assessed by the determination of the aortic pulse wave velocity (PWV), which is regarded as an important predictor of cardiovascular adverse events [1]. The pulse wave is generated by the systolic contraction of the left ventricle (LV) and travels through the aorta with a certain velocity depending on the constitution of the aortic wall. The aorta distends and stores the ejected blood and the elasticity of the aorta dampens the generated pulse wave in order to minimize the hydraulic demand on the LV ("Windkessel" function) [2]. A reduced aortic elasticity (higher aortic stiffness), as occurs with aging, leads to a higher aortic PWV and unfavorable effects on the heart and other organs. Aortic stiffness also increases earlier in life in the presence of cardiovascular risk factors and metabolic diseases [1, 2]. Another parameter that has been associated with increased cardiovascular risk is the amount of epicardial fat, which is the fat surrounding the heart and covered by the pericardium [3]. A metabolic and inflammatory role of this adipose tissue is discussed, and the amount of epicardial fat has also been related to age and obesity [4-6]. However, it is unclear if aortic PWV and the amount of epicardial fat are related with each other.

Cardiac magnetic resonance (CMR) allows the accurate assessment of these two parameters in a single examination. Aortic PWV can be determined by velocity-encoded CMR and the amount of epicardial fat can be accurately measured by a volumetric approach using a $3 \mathrm{D}$-mDixon pulse sequence $[7,8]$. The rationale of this quantitative cardiac magnetic resonance (CMR) study was to investigate a possible association between epicardial fat volume (EFV) and aortic PWV in healthy individuals within a single examination, and also to relate the results to body mass index (BMI) and age.

\section{Materials and Methods}

$\nabla$

The study protocol was approved by the local ethics committee. All scans were performed on a 1.5 Tesla (T) MR system (Ingenia, Philips Healthcare, Best, The Netherlands) with a maximum gradient strength of $45 \mathrm{mT} / \mathrm{m}$ and a maximum slew rate of $120 \mathrm{mT} /$ $\mathrm{m} / \mathrm{ms}$. A 32-channel torso coil with digital interface was used for signal reception. 58 consecutive healthy subjects with a wide BMI and age range but without known medical conditions, without history of cardiac disease and without chronic medications were examined. All participants had blood pressure within the normal range. Written informed consent was obtained from all study
EFV and PWV in patients with increased cardiovascular risk.

Key Points:

- EFV and PWV can be assessed in a single CMR exam.

$>$ EFV and aortic stiffness are both associated with cardiovascular risk.

$>$ EFV correlates with aortic stiffness, possibly due to similar proinflammatory mechanisms.

Citation Format:

- Homsi R, Thomas D, Gieseke J etal. Epicardial Fat Volume and Aortic Stiffness in Healthy Individuals: A Quantitative Cardiac Magnetic Resonance Study. Fortschr Röntgenstr 2016; 188: 853-858

participants prior to CMR. Exclusion criteria included contraindications for CMR and any evidence of cardiovascular pathologies.

\section{MRI acquisition}

Functional imaging

ECG-gated SSFP-cine images were obtained in breath-hold in the horizontal long axis, the vertical long axis, left ventricular outflow tract, and short axis for wall motion and functional analysis. The sequence parameters were as follows: field of view $(F O V)=350 \times 350 \mathrm{~mm}^{2}$, slice thickness $=8 \mathrm{~mm}$, pixel size $=1.7 \times 1.7 \mathrm{~mm}^{2}$, reconstructed to $1 \times 1 \mathrm{~mm}^{2}$, repetition time $(\mathrm{TR})=3.1 \mathrm{~ms}$, echo time $(\mathrm{TE})=1.6 \mathrm{~ms}$, flip angle $(\alpha)=60^{\circ}$, parallel imaging factor $(\mathrm{SENSE})=2.5$, number of cardiac phases reconstructed $=40$.

\section{Aortic PWV}

For the planning of the flow-encoded sequence, ECG-gated SSFP-cine images were acquired in a coronal and an oblique sagittal view, covering the aortic arch including the aorta ascendens (AA) and the proximal aorta descendens (AD). Based on these images, a 2D velocity-encoded MRI sequence was planned perpendicular through the $A A$ and $A D$ at the level of the bifurcation of the pulmonary artery with the following parameters: $F O V=300 \times 225 \mathrm{~mm}^{2}$, slice thickness $=8 \mathrm{~mm}$, pixel size $=1.7 \times 1.7 \mathrm{~mm}^{2}$, reconstructed to $1.2 \times 1.2 \mathrm{~mm}^{2}$, TR $=6.5 \mathrm{~ms}$, $\mathrm{TE}=2.2 \mathrm{~ms}, \alpha=15^{\circ}$, number of heart phases $=130$. Velocity encoding was set to a maximum velocity of $1.5 \mathrm{~m} / \mathrm{s}$. The scan time was $2-3 \mathrm{~min}$.

\section{Dixon chemical shift imaging}

For assessment of the epicardial fat volume, a 3D transverse ECGtriggered and respiratory navigator-gated magnetization prepared mDixon-sequence was acquired. The "gate and track" option of the scanner software was used, i.e. navigator gating was combined with prospective motion correction. Trigger delay was set to enddiastole and optimized by means of cine MRI data. The following sequence parameters were used: $\mathrm{FOV}=350 \times 302 \times 180 \mathrm{~mm}^{3}$, voxel size $=1.5 \times 1.5 \times 3.0 \mathrm{~mm}^{3}$ (120 overcontiguous slices $)$, reconstructed voxel size $=1.0 \times 1.0 \times 1.5 \mathrm{~mm}^{3}, \mathrm{TR}=5.4 \mathrm{~ms}, \mathrm{TE}_{1} / \mathrm{TE}_{2}=1.8 \mathrm{~ms} / 4.0 \mathrm{~ms}$; $\alpha=20^{\circ}$, parallel imaging factor (SENSE) $=1.5$ in both phase encoding directions, water fat shift $=0.16$ pixel, arrhythmia rejection was applied, T2 preparation $=50 \mathrm{~ms}$, acquisition window $=100-$ $156 \mathrm{~ms}$ (selected based on cine MRI data). The net scan duration was 3-5 min. With an assumed navigator efficiency of $40-50 \%$, the average total scan duration time was about $7.5 \mathrm{~min}$. In-phase (IP), opposed-phase (OP), water only (W), and fat only (F) images were reconstructed online at the scanner console [8]. 
Image Analysis

\section{Cardiac parameters}

The left ventricular end systolic and end diastolic volume (LVESV, LVEDV), LV function and LV myocardial mass as well as the peak filling rate were determined offline by manual tracing of the endocardial borders. Papillary muscles were included in the left ventricular cavity volume. Left ventricular function was assessed in all subjects by computation of the ejection fraction (LVEF) using the formula (LVEDV - LVESV)/ LVEDV $\times 100$. The peak filling rate was also adjusted for LVEDV by dividing it by the LVEDV resulting in a normalized peak filling rate (nPFR) $[9,10]$. Left ventricular volumes and mass were additionally normalized to the body surface area (BSA), yielding the LVESV index, LVEDV index and LV mass index (LVESVi, LVEDVi, LVMi).

\section{Aortic PWV}

PWV quantification was performed using a tool implemented in the software Segment (Segment, version 1.9, R3918; http://segment.heiberg.se) [11]. First, the path length of the aortic arch (aortic length $[A L]$ ), i. e. the distance between the section through the $A A$ and through the proximal $A D$, was measured between the center of the cross-sections of the AA and proximal AD. The time interval between the arrival of the velocity waveform at the section of the AA and at the section of the proximal AD is called the transit time (TT) and was determined by contour drawing in the aortic velocity maps. The TT is measured as the time between the intercept of the two calculated tangents with the time axis. The PWV was finally calculated by PWV $=\mathrm{AL} / \mathrm{TT}$ [7]. The post-processing time for the determination of the aortic PWV was about 5 minutes.

\section{Epicardial fat volume}

Dixon images were analyzed offline on a personal computer using dedicated software written in MATLAB (The MathWorks, Inc., Natick, MA) with an analysis time of about 7-10 minutes per subject. The epicardial fat volume was measured between the bifurcation of the pulmonary artery and the most inferior transverse slice of the myocardium [3]. A 3D region of interest
(ROI) was defined by manually contouring the epicardial border in each slice. Fat-fraction maps were computed based on fatand water-only images with an appropriate noise threshold and correction for relaxation effects to identify voxels predominantly containing fat. The epicardial fat volume was finally determined by multiplying the number of fat voxels inside the three-dimensional ROIs by the voxel size and was normalized to the BSA [8].

\section{Statistical Analysis}

Statistical analyses were performed in SPSS (IBM SPSS Statistics 22.0, Armonk, New York). Study participant characteristics are presented as mean \pm standard deviation or as absolute frequency. Group comparisons were made between younger (age $<45 \mathrm{y}$ ) and older subjects (age $>45 \mathrm{y}$ ) and between subjects with a BMI $<25 \mathrm{~kg} / \mathrm{m}^{2}$ and overweight subjects $\left(\mathrm{BMI}>25 \mathrm{~kg} / \mathrm{m}^{2}\right.$ ). Possible associations between the determined parameters were further assessed by analyses of covariance (ANCOVAs). A value of $p<0.05$ was considered statistically significant.

\section{Results \\ $\nabla$}

A total of 58 subjects ( 29 men, 29 women) were enrolled in this study. The mean age was $44.7 \pm 13.9 \mathrm{y}$ (range: 21 to $78 \mathrm{y}$ ) and the mean BMI was $25.5 \mathrm{~kg} / \mathrm{m}^{2}$ (range: 13.9 to $42.2 \mathrm{~kg} / \mathrm{m}^{2}$ ). The detailed characteristics of the study participants and CMR-derived parameters are summarized in $\bullet$ Table 1 in the column "overall". The mean values of the aortic PWV and EFV were $6.9 \pm 1.9 \mathrm{~m} / \mathrm{s}$ and $44.2 \pm 25.0 \mathrm{ml} / \mathrm{m}^{2}$. Examples of the measurements are shown in $\odot$ Fig. $1,2$.

Group comparisons according to age (cut-off $45 \mathrm{y}$ ) revealed that older subjects (mean age: $56.7 \pm 8.4 \mathrm{y}, \mathrm{n}=28$ ) had significantly higher aortic PWV and EFV values than younger individuals (mean age: $33.4 \pm 6.6 \mathrm{y}, \mathrm{n}=30$ ) with $\mathrm{PWV}=7.9 \pm 2.0 \mathrm{~m} / \mathrm{s}$ vs. $6.0 \pm$ $1.2 \mathrm{~m} / \mathrm{s}$ and $\mathrm{EFV}=54.7 \mathrm{ml} / \mathrm{m}^{2} \pm 27.1$ vs. $34.5 \mathrm{ml} / \mathrm{m}^{2} \pm 18.6(\mathrm{p}<$ 0.01 , each). There were no significant differences in BMI or sex between the two groups $(\mathrm{p}=0.83$ and $\mathrm{p}=0.30)$. By splitting the individuals into two groups according to BMI (cut-off $25 \mathrm{~kg} / \mathrm{m}^{2}$ ), over-

Table 1 Overall results and results in dependency of the body mass index (BMI) and age.

Tab. 1 Gesamtergebnisse sowie Ergebnisse nach Body Mass Index (BMI) und Alter

\begin{tabular}{|c|c|c|c|c|c|c|c|}
\hline parameters & overall & $\mathrm{BMI}>25$ & BMI $<25$ & $\mathbf{p}$ & age $>45$ & age $<45$ & $\mathbf{p}$ \\
\hline $\mathrm{n}$ & 58 & 30 & 28 & $\mathrm{n} / \mathrm{a}$ & 28 & 30 & $\mathrm{n} / \mathrm{a}$ \\
\hline men & 29 & 18 & 11 & 0.12 & 12 & 17 & 0.30 \\
\hline age (years) & $44.7 \pm 13.9$ & $44.7 \pm 13.2$ & $44.6 \pm 14.9$ & 0.97 & $56.7 \pm 8.4$ & $33.4 \pm 6.6$ & $<0.01$ \\
\hline BMI $\left(\mathrm{kg} / \mathrm{m}^{2}\right)$ & $25.5 \pm 4.8$ & $28.7 \pm 4.0$ & $21.9 \pm 2.5$ & $<0.01$ & $25.3 \pm 4.0$ & $25.6 \pm 5.5$ & 0.83 \\
\hline aortic PWV (m/s) & $6.9 \pm 1.9$ & $7.2 \pm 1.8$ & $6.6 \pm 1.9$ & 0.20 & $7.9 \pm 2.0$ & $6.0 \pm 1.2$ & $<0.01$ \\
\hline $\operatorname{EFV}\left(\mathrm{ml} / \mathrm{m}^{2}\right)$ & $44.2 \pm 25.0$ & $56.1 \pm 27.1$ & $31.5 \pm 14.6$ & $<0.01$ & $54.7 \pm 27.1$ & $34.5 \pm 18.6$ & $<0.01$ \\
\hline $\operatorname{LVEF}(\%)$ & $63.3 \pm 5.2$ & $63.1 \pm 4.6$ & $63.8 \pm 5.6$ & 0.59 & $65.4 \pm 4.7$ & $61.6 \pm 4.8$ & $<0.01$ \\
\hline LVEDVi $\left(\mathrm{ml} / \mathrm{m}^{2}\right)$ & $71.9 \pm 13.8$ & $68.5 \pm 13.2$ & $75.8 \pm 13.0$ & $<0.05$ & $70.1 \pm 13.3$ & $73.8 \pm 13.7$ & 0.31 \\
\hline LVESVi $\left(\mathrm{ml} / \mathrm{m}^{2}\right)$ & $26.9 \pm 7.4$ & $26.0 \pm 7.4$ & $27.8 \pm 7.0$ & 0.35 & $24.7 \pm 7.2$ & $28.8 \pm 6.7$ & $<0.05$ \\
\hline heart rate (bpm) & $68.1 \pm 11.0$ & $68.6 \pm 11.4$ & $66.6 \pm 10.5$ & 0.50 & $66.3 \pm 11.7$ & $68.7 \pm 10.3$ & 0.41 \\
\hline systolic BP (mmHg) & $117.5 \pm 14.1$ & $125.2 \pm 8.6$ & $120.5 \pm 11.4$ & 0.42 & $126.6 \pm 10.1$ & $119.2 \pm 11.6$ & 0.12 \\
\hline diastolic BP (mmHg) & $72.6 \pm 7.2$ & $74.0 \pm 7.5$ & $74.8 \pm 4.5$ & 0.82 & $73.1 \pm 8.4$ & $75.7 \pm 7.4$ & 0.45 \\
\hline IVST (mm) & $8.9 \pm 1.5$ & $9.3 \pm 1.5$ & $8.6 \pm 1.4$ & 0.09 & $9.0 \pm 1.5$ & $9.0 \pm 1.5$ & 0.97 \\
\hline LVM (g) & $100.6 \pm 29.3$ & $108.8 \pm 28.9$ & $91.9 \pm 27.6$ & 0.03 & $93.8 \pm 27.6$ & $107.0 \pm 29.9$ & 0.09 \\
\hline $\operatorname{LVMi}\left(\mathrm{g} / \mathrm{m}^{2}\right)$ & $52.3 \pm 11.8$ & $53.2 \pm 11.4$ & $51.3 \pm 12.3$ & 0.54 & $50.1 \pm 11.0$ & $54.4 \pm 12.3$ & 0.17 \\
\hline nPFR & $2.7 \pm 1.0$ & $2.8 \pm 1.2$ & $2.6 \pm 0.8$ & 0.29 & $2.3 \pm 1.0$ & $3.1 \pm 0.9$ & $<0.05$ \\
\hline
\end{tabular}

BMI: Body mass index; LVEF: Left ventricular ejection fraction; LVEDVi: Left ventricular end diastolic volume/body surface area ( $\left.\mathrm{ml} / \mathrm{m}^{2}\right)$; LVESVi: Left ventricular end systolic volume/ body surface area (ml/m²); IVST: Interventricular septal thickness; Aortic PWV: Aortic pulse wave velocity; EFV: epicardial fat volume (ml/m²); BP: blood pressure; bpm: beats per minute; LVM: left ventricular mass (g); LVMi: left ventricular mass/body surface area $\left(\mathrm{g} / \mathrm{m}^{2}\right)$; nPFR: normalized peak filling rate. 

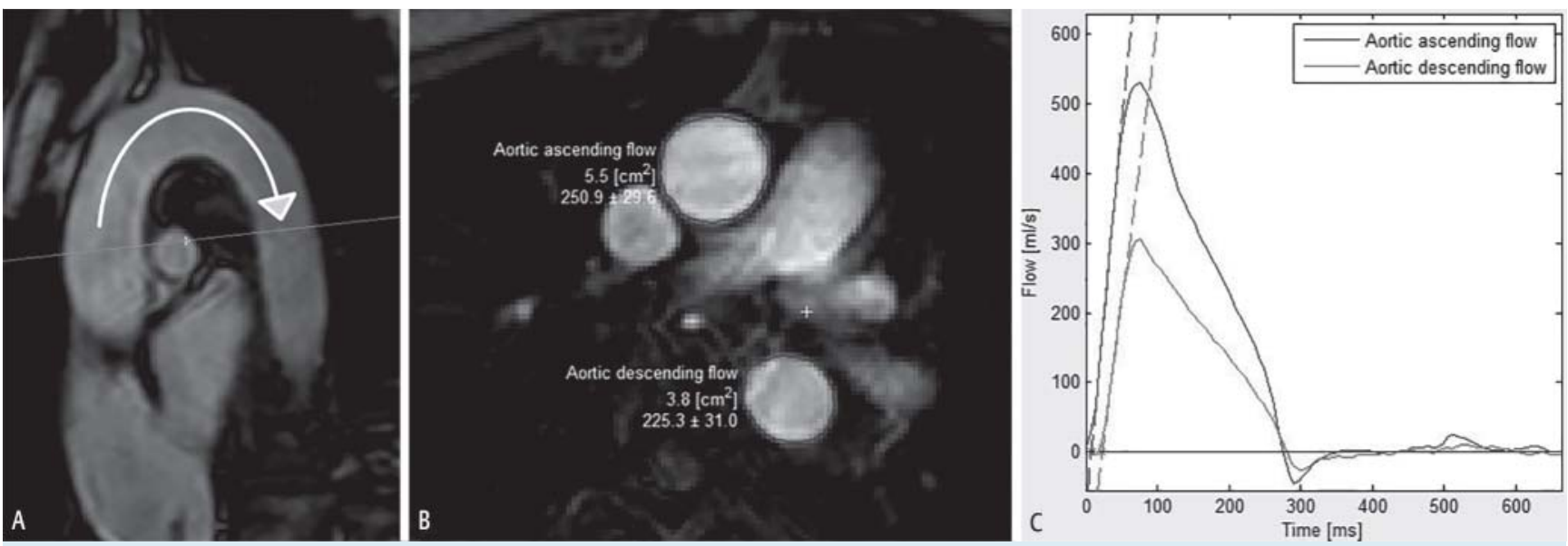

Fig. 1 PWV quantification in a 51-year-old female (Segment, version 1.9, R3918; http://segment.heiberg.se). The aortic length is measured between the section through the ascending and proximal descending aorta $\mathbf{A}$. Using the velocity maps at the respective regions of interest $\mathbf{B}$, the corresponding flow curves can be plotted C. PWV is calculated by dividing the transit time between the two tangents by the aortic length: PWV = aortic length / transit time.

Abb. 1 PWV Quantifizierung bei einer 51-jährigen Frau (Segment, version 1.9, R3918; http://segment.heiberg.se). Die aortale Länge wird im Bereich der Flussmessungen zwischen der Aorta ascendens und descendens gemessen A. Anhand der jeweiligen Flussmessung B kann die korrespondierende Flusskurve dargestellt werden C. Die aortale PWV ergibt sich aus Division der aortalen Länge und dem Zeitversatz zwischen den Tangenten der Flusskurven in Aorta ascendens und descendens: PWV = aortale Länge / Transitzeit
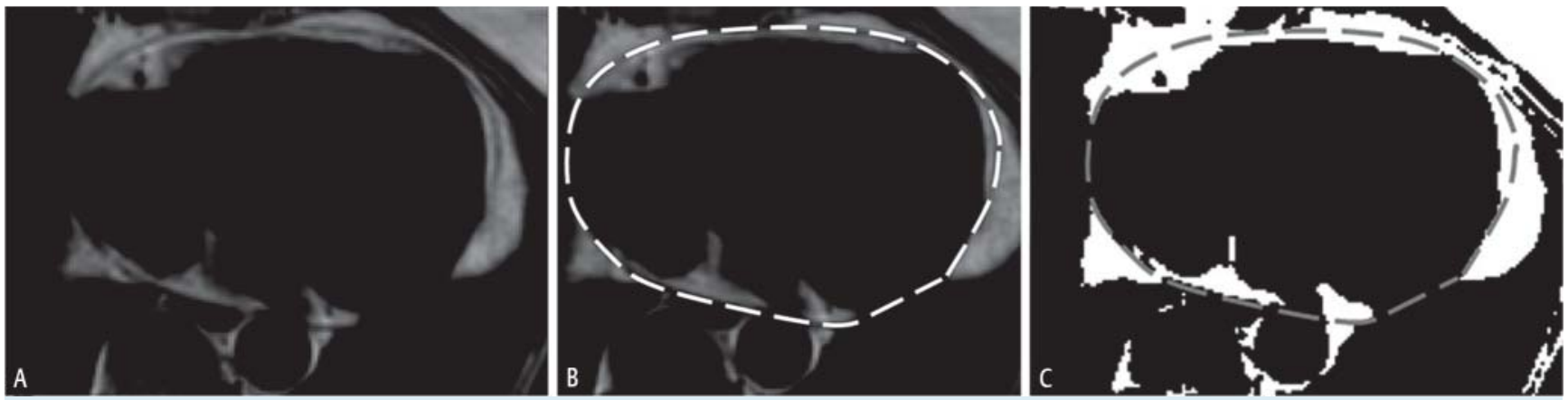

Fig. 2 Dixon images in a 61-year-old female. A: Fat only image. B: Fat only image with the epicardial outlines. C: Segmented fat voxels with the transferred region of interest.

Abb.2 Dixon Bilder einer 61 jährigen Frau. A: Fettbild. B: Fettbild mit eingezeichneter Begrenzung des Epikards. C: Segmentierte Fettvoxel mit übertragener Region of Interest.

weighted individuals $(\mathrm{n}=30)$ had significantly higher EFV values than non-overweighted subjects (mean BMI $21.9 \pm 2.5 \mathrm{~kg} / \mathrm{m}^{2}$, $\mathrm{n}=28)$ with $E F V=56.1 \pm 27.1 \mathrm{ml} / \mathrm{m}^{2}$ vs. $31.5 \pm 14.6 \mathrm{ml} / \mathrm{m}^{2}(\mathrm{p}<$ 0.01). No significant difference in PWV was observed between the two BMI groups $(p=0.20)$. The complete results of the two group comparisons including all determined cardiac parameters are summarized in $\bullet$ Table 1.

Analyses of covariance with PWV and EFV as dependent variables and BMI and age as independent variables confirmed an association between EFV and BMI ( $<<0.001)$, and that PWV and EFV were both significantly associated with age $(\mathrm{p}<0.001$, each). PWV was higher in subjects with an increased epicardial fat volume. This association was statistically significant, also after adjustment for age effects $(\mathrm{p}=0.025)$.

\section{Discussion}

$\nabla$

CMR is not widely used for the evaluation of cardiovascular risk parameters such as aortic stiffness and the amount of epicardial fat, even though CMR has several advantages. With the 3D-Dixon technique, for instance, it is possible to measures the whole epicardial fat volume without the use of ionizing radiation (in contrast to $\mathrm{CT}$ ). In echocardiography only the thickness of the epicardial fat is determined as a diameter at a specific location $[3,8]$. Additionally, with CMR the PWV can be assessed in particular aortic segments, whereas tonometric devices measure a more general arterial stiffness, as this includes different superficial locations such as between the carotid or brachial artery and the femoral artery. These arteries, however, are also muscular vessels and involve muscular stiffening with a consecutively greater variance of the measured PWV. Also the real path length of the pulse wave can only be estimated $[1,7,12,13]$.

The MR sequences on which the above named measurements are based (3D-Dixon and velocity-encoded CMR) can easily be integrated into the routine workflow of a CMR study. This is a clear advantage of CMR, as all measurements can be performed in a single examination, in contrast to other approaches which necessitate the application of different modalities $[1,3,7]$. 
In the present study, the aortic PWV and the epicardial fat volume were determined in healthy individuals. A statistically significant association was found not only between aortic PWV and age, and between epicardial fat volume and age and BMI, but also between epicardial fat volume and aortic PWV.

Increased aortic stiffness (and aortic PWV) occurs physiologically with aging and begins first at the level of the aorta ascendens and the aortic arch. The mechanisms are partly explained by intima media hypertrophy, sclerosis and changes of the extracellular matrix with replacement of elastin by collagen. Metabolic and general inflammatory mechanisms also play a role by leading to impaired arterial function and atherosclerosis $[1,2,14]$. These changes have unfavorable effects on the heart. As a consequence of the higher aortic stiffness, the afterload increases thus reducing the diastolic blood pressure and the coronary blood flow. This is further complicated when LV hypertrophy or coronary artery disease is also present. An increased PWV also occurs earlier in life in the presence of cardiovascular risk factors and metabolic diseases. PWV is one of the most important predictors of cardiovascular adverse events and an important diagnostic step in evaluating cardiovascular risk $[1,13]$. Concerning BMI, previous studies observed inconsistent results [1, 15-17]. Although our CMRbased results demonstrated a strong association between aortic PWV and age, there was no significant relationship between aortic PWV and BMI. The lack of an association may be explained by the fact that all persons were healthy and a higher BMI does not necessarily lead to changes in the vasculature and higher arterial stiffness. It rather reflects the co-occurrence of other cardiovascular risk factors, which is more prevalent in obese persons $[18,19]$. This may also explain why left ventricular mass index and nPFR as a measure of diastolic function - did not differ significantly between the two BMI groups. None of the overweighted subjects had additional cardiovascular risk factors. Age was associated with a reduced nPFR. However, a somewhat reduced diastolic dysfunction may be regarded as a physiologic process in aging due to age-related structural and functional cardiac changes [9].

We observed that aging was also associated with an increase in epicardial fat volume which may be due to a loss of lean body mass with an increase in fat mass and redistribution to the trunk and viscera which occurs with aging [20]. In contrast to the aortic $P W V$, the epicardial fat volume was significantly associated with BMI which is in concordance with previous studies [21, 22]. We also observed a significant relationship between the epicardial fat volume and the aortic PWV. The mechanisms behind this relationship, however, are unclear. Possible mechanisms may be metabolic and inflammatory [23, 24]. Under normal circumstances, epicardial adipose tissue serves as a physiologic energy source and has beneficial effects through adipokines which are regarded as being anti-atherogenic and anti-inflammatory [4, 25]. With a substantial increase, these effects can unfavorably change its metabolic activity. Increased insulin resistance has been observed with an increased amount of epicardial fat and also with increased visceral fat in general $[26,27]$. This increased insulin resistance is associated with vascular smooth muscle cell growth, glycation of the proteins in the arterial wall with consecutive organ damage and atherosclerosis, inhibition of the ability of insulin to elicit endothelium-dependent vasodilation. Consequently, the possibility for injury to the vessel wall and vessel wall stiffening is increased [16, 17, 28, 29].

Furthermore, the hypertrophied epicardial fat becomes hypoxic and dysfunctional, it reduces its secretion of anti-atherosclerotic adipokines, such as adiponectin, and additionally becomes inva- ded by inflammatory factors such as by an increased number of macrophages, fibroblasts, mast cells, lymphocytes and proinflammatory cytokines (such as TNF- $\alpha$, MCP-1, IL-1 $\beta$, IL-6). This increased inflammatory activity may contribute to aortic atherogenesis, atherosclerosis and aortic stiffness by inflammation in the vascular wall, $[4,25,30]$. However, a local metabolic and inflammatory activity of the epicardial adipose tissue through the same mechanisms may also play a role, as epicardial fat has direct contact with the coronary arteries, the aorta and the myocardium and also shares the same blood supply with the myocardium $[22,30]$. All together, these metabolic and inflammatory mechanisms may explain the observed association between the amount of epicardial fat and the aortic PWV as a measure for aortic stiffness.

\section{Limitations \\ $\nabla$}

In our study we only investigated healthy persons and future studies have to concentrate on patients with increased cardiovascular risk, such as hypertension or diabetes mellitus, in order to reveal relationships concerning aortic stiffness and epicardial fat in the presence of such risk factors. The low number of subjects examined in this study is also a limitation. However, the inclusion of healthy subjects with a wide BMI and age range made it possible to study associations with the obtained measures.

\section{Conclusion}

Epicardial fat volume and aortic stiffness are both associated with age, but also with each other, independent of age. Metabolic and inflammatory mechanisms found with increased epicardial fat may promote the development of atherosclerosis and aortic stiffness. A combined measurement of aortic PWV and epicardial fat volume as parameters of cardiovascular risk is feasible. Future studies should concentrate on these relationships in patients with increased cardiovascular risk and disease and with regard to the prediction of cardiovascular events. CMR provides a valuable tool for such studies.

\section{Clinical relevance}

Epicardial fat and aortic stiffness are associated with each other, independent of age.

- With CMR, epicardial fat volume and aortic stiffness can be determined in a single exam.

$\checkmark$ A combined measurement of PWV and EFV can easily be integrated in a routine CMR.

- A CMR-based assessment of PWV and EFV may in the future be helpful in cardiovascular risk stratification.

\section{References}

1 Laurent S, Cockcroft J, Van Bortel L et al. Expert consensus document on arterial stiffness: methodological issues and clinical applications. Eur Heart J 2006; 27: 2588-2605

2 O'Rourke $M$. Mechanical principles in arterial disease. Hypertension 1995; 26: $2-9$

3 Dey $D$, Nakazato $R$, Li D et al. Epicardial and thoracic fat - Noninvasive measurement and clinical implications. Cardiovasc Diagn Ther 2012; 2: $85-93$ 
4 Iacobellis G, Bianco AC. Epicardial adipose tissue: emerging physiological, pathophysiological and clinical features. Trends Endocrinol Metab 2011; 22: 450-457

5 Mazurek T, Zhang L, Zalewski A et al. Human epicardial adipose tissue is a source of inflammatory mediators. Circulation 2003; 108: 24602466

6 Iacobellis G, Pistilli D, Gucciardo $M$ et al. Adiponectin expression in human epicardial adipose tissue in vivo is lower in patients with coronary artery disease. Cytokine 2005; 29: 251 -255

7 Wentland AL, Grist TM, Wieben O. Review of MRI-based measurements of pulse wave velocity: a biomarker of arterial stiffness. Cardiovasc Diagn Ther 2014; 4: 193-206

8 Homsi R, Meier-Schroers M, Gieseke J et al. 3D-Dixon MRI based volumetry of peri- and epicardial fat. Int J Cardiovasc Imaging 2015; 85: 936- 942

9 Maceira AM, Prasad SK, Khan M et al. Normalized left ventricular systolic and diastolic function by steady state free precession cardiovascular magnetic resonance. J Cardiovasc Magn Reson 2006; 8: 417-426

10 Rokey R, Kuo LC, Zoghbi WA et al. Determination of parameters of left ventricular diastolic filling with pulsed Doppler echocardiography: comparison with cineangiography. Circulation 1985; 71: 543-550

11 Dorniak K, Hellmann M, Rawicz-Zegrzda D et al. A novel tool for phase contrast MR-derived pulse wave velocity measurement - validation against applanation tonometry and phantom studies. Journal of Cardiovascular Magnetic Resonance 2015; 17: P40

12 Liu CS, Li CI, Shih CM et al. Arterial stiffness measured as pulse wave velocity is highly correlated with coronary atherosclerosis in asymptomatic patients. J Atheroscler Thromb 2011; 18: 652-658

13 Baulmann J, Homsi R, Uen S et al. Pulse wave velocity is increased in patients with transient myocardial ischemia. J Hypertens 2006; 24: $2085-2090$

14 McEniery CM, Yasmin Hall IR et al. Normal vascular aging: differential effects on wave reflection and aortic pulse wave velocity: the AngloCardiff Collaborative Trial (ACCT). Journal of the American College of Cardiology 2005; 46: 1753-1760

15 Zebekakis PE, Nawrot T, Thijs L et al. Obesity is associated with increased arterial stiffness from adolescence until old age. J Hypertens 2005; 23: 1839-1846

16 Wildman RP, Mackey RH, Bostom A et al. Measures of obesity are associated with vascular stiffness in young and older adults. Hypertension 2003; 42: $468-473$

17 Ferreira I, Snijder MB, TwiskJW et al. Central fat mass versus peripheral fat and lean mass: opposite (adverse versus favorable) associations with arterial stiffness? The Amsterdam Growth and Health Longitudinal Study. J Clin Endocrinol Metab 2004; 89: 2632 - 2639
18 Dyer AR, Elliott $P$. The INTERSALT study: relations of body mass index to blood pressure. INTERSALT Co-operative Research Group. J Hum Hypertens 1989; 3: 299-308

19 Cutler JA, Sorlie PD, Wolz $M$ et al. Trends in hypertension prevalence, awareness, treatment, and control rates in United States adults between 1988-1994 and 1999-2004. Hypertension 2008; 52: 818-827

20 Perissinotto E, Pisent C, Sergi G et al. Anthropometric measurements in the elderly: age and gender differences. Br J Nutr 2002; 87: 177-186

21 Silaghi A, Piercecchi-Marti MD, Grino $M$ et al. Epicardial adipose tissue extent: relationship with age, body fat distribution, and coronaropathy. Obesity (Silver Spring) 2008; 16: 2424-2430

22 Rosito GA, Massaro JM, Hoffmann U et al. Pericardial fat, visceral abdominal fat, cardiovascular disease risk factors, and vascular calcification in a community-based sample: the Framingham Heart Study. Circulation 2008; 117: 605-613

$23 \mathrm{Kim}$ BJ, Kim BS, Kang JH. Echocardiographic epicardial fat thickness is associated with arterial stiffness. International journal of cardiology 2013; 167: 2234-2238

24 Park HE, Choi SY, Kim HS et al. Epicardial fat reflects arterial stiffness: assessment using 256-slice multidetector coronary computed tomography and cardio-ankle vascular index. J Atheroscler Thromb 2012; 19: 570-576

25 Fitzgibbons TP, Czech MP. Epicardial and perivascular adipose tissues and their influence on cardiovascular disease: basic mechanisms and clinical associations. Journal of the American Heart Association 2014; 3: e000582

26 Choi KM, Lee KW, Seo JA et al. Relationship between brachial-ankle pulse wave velocity and cardiovascular risk factors of the metabolic syndrome. Diabetes Res Clin Pract 2004; 66: 57-61

27 Nakanishi N, Suzuki K, Tatara K. Clustered features of the metabolic syndrome and the risk for increased aortic pulse wave velocity in middle-aged Japanese men. Angiology 2003; 54: 551 - 559

28 Begum N, Song Y, Rienzie J et al. Vascular smooth muscle cell growth and insulin regulation of mitogen-activated protein kinase in hypertension. Am J Physiol 1998; 275: C42 - C49

29 Ulrich P, Cerami A. Protein glycation, diabetes, and aging. Recent Prog Horm Res 2001; 56: 1-21

30 Talman AH, Psaltis PJ, Cameron JD et al. Epicardial adipose tissue: far more than a fat depot. Cardiovasc Diagn Ther 2014; 4: 416-429 